\title{
Image of a pacemaker that was externally manipulated by the patient
}

\section{Imágenes de la manipulación externa de un marcapasos por parte del paciente}

\author{
Fernando D. Berdaguer-Ferrari* and Julio Badie \\ Intensive Care Unit, Hôpital Nord Franche-Comté, Trévenans, France
}

Figure 1 corresponds to a 77-year-old female patient with a history of psychiatric and neurocognitive disorders, multiple visits to the emergency department, and hospitalizations for social rather than medical causes. In addition, she had a pacemaker implanted in March 2018 for bradycardia in the context of a 2:1 atrioventricular block. In January 2019, the patient was hospitalized for general weakness after a gastrointestinal disorder; ECG revealed atrial fibrillation and signs of double-chamber pacemaker sensing and capture

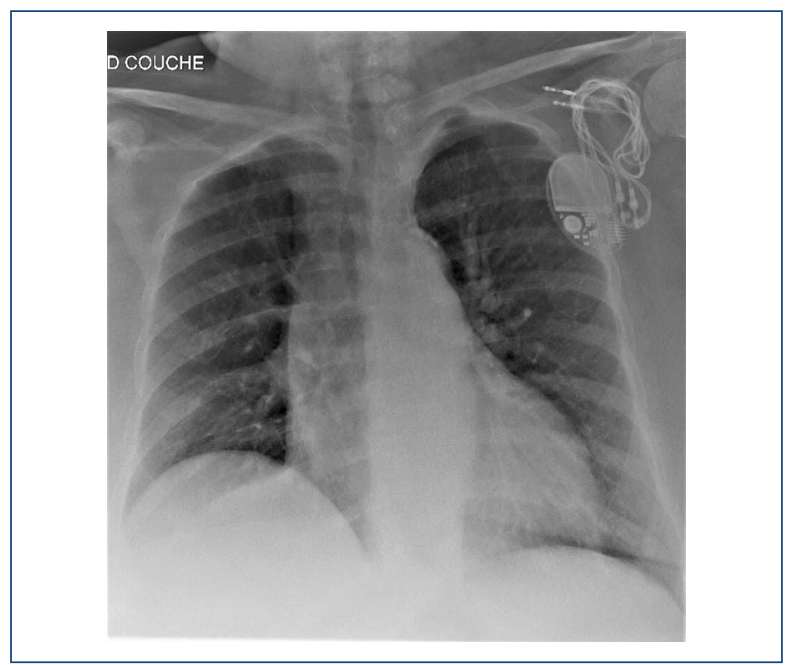

Figure 1. Patient chest X-ray. On left sub-clavicular region, the pacemaker leads are observed to be completely outside the heart. D: right; COUCHE: "lying down" in French. dysfunction, with pacemaker spikes dissociated from patient basal rhythm (Fig. 2). As it can be observed in figure 1, the patient shows pacemaker leads dislodgement, confirmed by herself, secondary to multiple rotations on its axis by external manipulation, an alteration known as twiddler syndrome ${ }^{1,2}$. A new pacemaker was implanted shortly after and the patient was discharged (Fig. 3).

The twiddler syndrome corresponds to an unusual pacemaker failure resulting from dislodgement of its leads. There are only few reports about this event, most often related to patients suffering from dementia or psychiatric disorders of the obsessive-compulsive type and

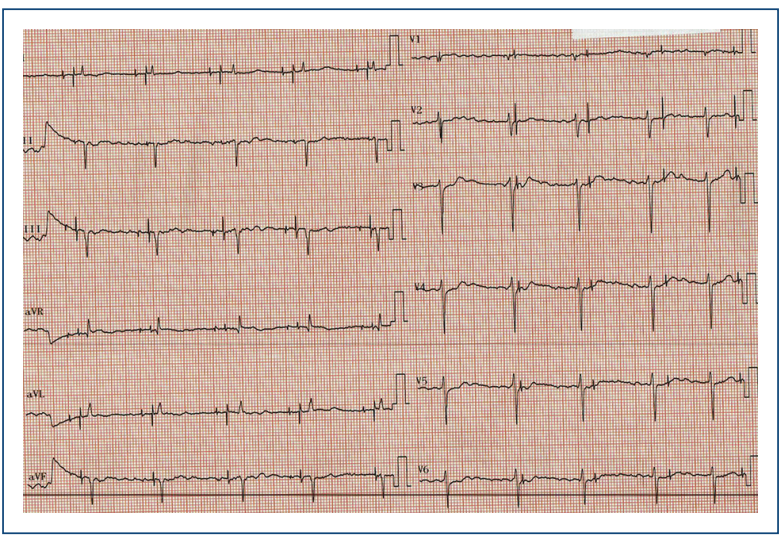

Figure 2. Patient electrocardiogram at admission revealing an atrial fibrillation rhythm of $\sim 63 \mathrm{bpm}$, with dual-chamber pacemaker spikes showing sensing and capture defect.

\section{Correspondence:}

*Fernando D. Berdaguer Ferrari

E-mail: fberdaguer@hotmail.com
Available online: 19-07-2021

Arch Cardiol Mex (Eng). 2021;91(2):206-207

www.archivoscardiologia.com 2604-7063 / ๑ 2020 Instituto Nacional de Cardiología Ignacio Chávez. Published by Permanyer. This is an open access article under the CC BY-NC-ND license (http://creativecommons.org/licenses/by-nc-nd/4.0/). 


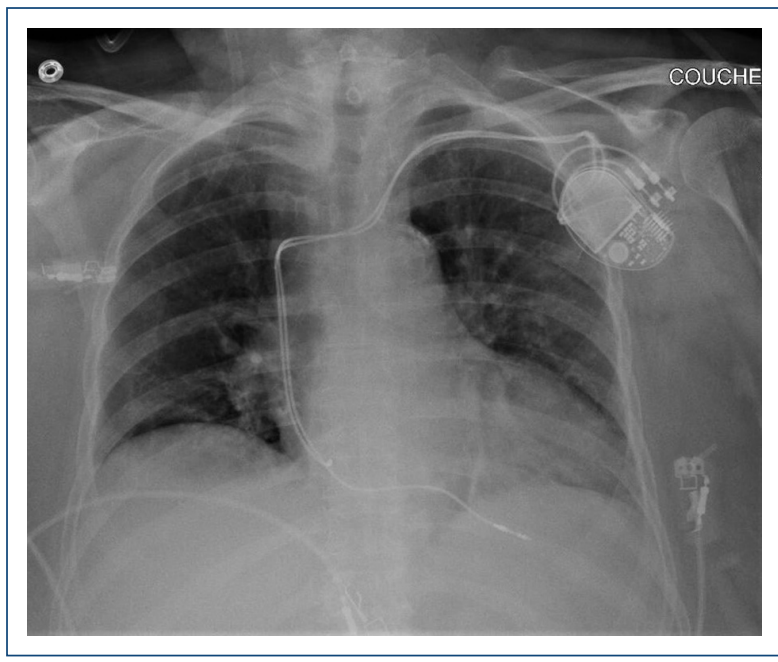

Figure 3. Chest X-ray after new pacemaker implantation. COUCHE: "lying down" in French.

who attend outpatient services with various clinical conditions, from syncope episodes to involuntary chest muscle contractions, or even asymptomatic cases. Other variants of pacemaker dysfunction by dislodgement can include the reel syndrome (coiling), in which dislodgement is also an effect of external manipulation, but on transverse axis, rather than long axis as in twiddler syndrome, or ratchet syndrome, which is not a consequence of manipulation by the patient but of ipsilateral arm usual movements, along with possible generator fixation defects, which favors lead dislodgement ${ }^{3}$.

\section{Funding}

This research has not received any specific grant from public, commercial, or non-profit sector agencies.

\section{Conflicts of interest}

The authors declare that they have no conflict of interests.

\section{Ethical disclosures}

Protection of human and animal subjects. The authors declare that no experiments have been performed on humans or animals for this research.

Confidentiality of data. The authors declare that they have followed the protocols of their work center on the publication of patient data.

Right to privacy and informed consent. The authors declare that no patient data appear in this article.

\section{References}

1. Bayliss CE, Beanlands DS, Baird R. The pacemaker-ywiddler's syndrome: a new complication of implantable transvenous pacemakers. Canadian Medical Association Journal. 1968;24;99(8):371.

2. Castillo R, Cavusoglu E. Twiddler's syndrome: an interesting cause of pacemaker failure. Cardiology. 2006;105(2):119-21.

3. Arias MA, Pachón M, Puchol A, Jiménez-López J, Rodríguez-Picón B, Rodríguez-Padial L. Ordenación terminológica sobre macrodislocación de electrodos de dispositivos cardiacos electrónicos implantables. Revista Española de Cardiología. 2012;65(7):671-673. 